\title{
Call for experts to join the Scientific Panels of the European Food Safety Authority - deadline extended to 7 July 2014
}

Eurosurveillance editorial team (eurosurveillance@ecdc.europa.eu) ${ }^{1}$

1. European Centre for Disease Prevention and Control (ECDC) Stockholm, Sweden

Citation style for this article:

Eurosurveillance editorial team. Call for experts to join the Scientific Panels of the European Food Safety Authority - deadline extended to 7 July 2014 . Euro Surveill. 2014;19(23):pii=20827. Available online: http://www.eurosurveillance.org/ViewArticle.aspx?Articleld=20827 published on 12 June 2014

The European Food Safety Authority (EFSA) is extending the deadline of its call for experts, launched in April 2014.

EFSA is looking for scientific experts for membership of its Scientific Committee and the following eight Scientific Panels: Additives and products or substances used in animal feed (FEEDAP), Animal health and welfare (AHAW), Biological hazards (BIOHAZ), Contaminants in the food chain (CONTAM), Dietetic products, nutrition and allergies (NDA), Genetically modified organisms (GMO), Plant health (PLH) and Plant protection products and their residues (PPR).

The current members of the Scientific Committee and Panels are serving a three-year term that is due to expire in mid-2015. The new members will be appointed for the following three-year period starting in July 2015.

Applications are invited on the EFSA website (http:// www.efsa.europa.eu/en/scpanels/memberscall 2011. htm) by 7 July 2014. Official notification of the extension of the call will be published shortly in the Official Journal of the European Union. 